\title{
Adaptive Market Hypothesis and Return Predictability: A Hidden Markov Model Application in Borsa Istanbul1
}

\author{
Hasan Arda BURHAN (https://orcid.org/0000-0003-4043-2652), Department of Econometrics, Kütahya \\ Dumlupınar University, Turkey; e-mail: arda.burhan@dpu.edu.tr
}

Eylem ACAR (https://orcid.org/0000-0003-0863-9143), Department of Econometrics, Kütahya Dumlupınar

University, Turkey; e-mail: eyacar@gmail.com

\section{Adaptif Piyasa Hipotezi ve Getiri Öngörülebilirliği: Borsa İstanbul İçin Bir Gizli Markov Modeli Uygulaması}

\begin{abstract}
The adaptive market hypothesis (AMH) has recently attracted significant interest in the financial literature. The AMH has started to be considered an alternative to the efficient market hypothesis. In this respect, this study, first of all, examines the AMH for the BIST100 index of Turkey's Borsa Istanbul stock exchange market by testing the return predictability. The applications are performed via automatic portmanteau and the generalized spectral (GS) tests using daily closing price data between January 1988 and December 2017. Secondly, the results of these tests are utilized for a hidden Markov model (HMM) application to examine the periods that yield return predictability. According to the results, it is observed that there is strong evidence for the validity of AMH within the scope of Borsa Istanbul's BIST100. Additionally, the results of the HMM application confirm the periodic predictability regarding the determinants of the index.
\end{abstract}

Keywords

JEL Classification Codes :
Adaptive Market Hypothesis, Return Predictability, Hidden Markov Models, Borsa Istanbul, BIST100.

$$
\text { G1, G14, C12, C44. }
$$

\section{$\ddot{\mathbf{O z}}$}

Adaptif piyasa hipotezi (APH) güncel finansal literatürde belirgin bir ilgi görmektedir. Bu durum APH'nin yine finansal literatürde sıklıkla araştırma konusu olan etkin piyasa hipotezine bir alternatif olarak ortaya çıkmış olması ile bağlantılıdır. Bu doğrultuda çalışmada, ilk olarak Borsa İstanbul hisse senedi piyasas1 BIST100 endeksi için APH, getiri öngörülebilirliğinin test edilmesi yoluyla incelenmiştir. Bu bağlamda Ocak 1988 - Aralık 2017 arası günlük kapanış fiyatı verilerine otomatik portmanteau ve genelleştirilmiş spektral (GS) testleri uygulanmıştır. Analizin devamında bu testlerin sonuçları, getiri öngörülebilirliği sağlayan dönemleri incelemek için bir gizli Markov model (GMM) uygulamasında kullanılmıştır. Sonuçlara göre Borsa İstanbul'un APH'ne güçlü bir şekilde uyum sağladığı görülmüştür. Ek olarak, GMM uygulamasının sonuçları, endeksin belirleyicileri ile ilgili olarak da periyodik öngörülebilirliği doğrulamıştır.

This study is derived from the doctoral dissertation of Hasan Arda Burhan entitled "A Hidden Markov Model Approach in the Context of Adaptive Market Hypothesis: An Evidence from Borsa Istanbul", supervised by Eylem Acar in Kütahya Dumlupinar University, Institute of Social Sciences, 19/11/2018.

2 Bu çalışma Hasan Arda Burhan'ın 19/11/2018 tarihinde Kütahya Dumlupinar Üniversitesi Sosyal Bilimler Enstitüsü’nde Eylem Acar danışmanlığında savunulan “Adaptif Piyasa Hipotezi Bağlamında Gizli Markov Modeli Yaklaşımı: Borsa İstanbul Örneği” başlıklı doktora tezine dayanarak hazırlanmıştır. 
Burhan, H.A. \& E. Acar (2021), “Adaptive Market Hypothesis and Return Predictability:

A Hidden Markov Model Application in Borsa Istanbul”, Sosyoekonomi, 29(48), 31-58.

\begin{abstract}
Anahtar Sözcükler $\quad$ : Adaptif Piyasa Hipotezi, Getiri Öngörülebilirliği, Gizli Markov Modelleri, Borsa İstanbul, BIST100.
\end{abstract}

\title{
1. Introduction
}

The predictability of stock returns has been one of the core inquiries in economics and finance. Given the related literature, the efficient market hypothesis (EMH) of Fama (1970) can be regarded as the focal point of a broad range of studies in which the return predictability of these financial assets has been investigated. The EMH asserts that, in an efficiently operated market, asset prices reflect all available information and therefore, market participants cannot benefit from the available information sets to predict future prices and returns (Urquhart \& Hudson, 2013). According to the well-known threefold distinction of Fama (1970), the strong form efficiency bases on private information, while the semistrong form includes publicly available information, and the weak form, which is the most commonly tested form of the EMH, deals with the prices and returns of past periods. Along with the adjustment of prices in compliance with this historical information, the returns become unpredictable since prices follow a random walk (Charles et al., 2012: 1608).

However, opposing arguments have been presented in the literature and by considering the stochastic feature of asset prices, the validity of EMH was started to be questioned in various studies. Accordingly, some scholars began to develop models by taking irrational human behaviours into consideration such as overreaction and overconfidence, which later led to the development of behavioural finance (Shiller, 2003: 90; Kim et al., 2011: 868). The main idea behind this approach was the difficulty in defining rationality, which brings about the realization of the unrealistic nature of the EMH (Farmer \& Lo, 1999: 9991-9992). However, there was a lack of an alternative theory in behavioural finance until Lo (2004) combined the time-varying property of market efficiency and return predictability with a behavioural perspective in a new concept, namely the adaptive market hypothesis (AMH).

Along with the acknowledgment that the return predictability may appear occasionally because of changing market conditions, it can be stated that the AMH associates the EMH with Simon's (1955) notion of bounded rationality, as the decision-makers in the market prefer satisfying options rather than optimal ones due to probable difficulties of accessing information in an unstable market environment (Charles et al., 2012: 1608-1609; Rahman et al., 2017: 180). Also, the AMH incorporates the evolutionary principles to its perspective for the determination of the state in which the decision-makers' behaviour is satisfactory (Lo, 2004). In this context, while certain behaviours such as overconfidence, loss aversion, overreaction are regarded as breaches of rationality and thereby presents an incompatibility to the $\mathrm{EMH}$, these reactions are tolerated in the AMH because of their consistency with the evolutionary model (Zhou \& Lee, 2013: 1650; Ghazani \& Araghi, 2014: 52). According to AMH, individuals adapt to the changing conditions of the market environment through trial errors and natural selection by competing, learning from their mistakes, and relying on heuristics (Kim et al., 2011: 869). Therefore, individuals in the 
market should be characterized as neither perfectly rational nor irrational, however foreseeing and intelligent competitors that adapt to the habitat (Lo, 2012: 24). As the profit opportunities deplete due to competition, new opportunities will be created with the help of natural selection (Urquhart \& Hudson, 2013: 130; Urquhart \& McGroarty, 2016: 39). However, this state of affairs should not be taken as a progression to an ideal condition, because of the fact that in $\mathrm{AMH}$, eventual stability and equilibrium are neither likely to happen nor ensured such as in evolutionary biology (Lo, 2005: 33).

In order to examine the AMH, tests that seek linear and/or nonlinear dependence in returns are widely used in the literature usually along with the moving (rolling) sub-sample window approach (see Lim \& Brooks, 2006; Todea et al., 2009; Kim et al., 2011; Lim et al., 2013; Urquhart \& Hudson, 2013; Zhou \& Lee, 2013; Charles et al., 2017; Gyamfi, 2018). According to these studies in which the return patterns are analysed over a period, the related market(s) will be qualified as adaptive if at least three different periods of return predictability (e.g. predictable, unpredictable, predictable) are observed (Urquhart \& Hudson, 2013: 131). In other words, if the market(s) switch between efficiency and inefficiency over time, the AMH can be verified (Ramírez et al., 2015: 391-392). Therefore, it can be stated that the AMH is also investigated by measuring the degree of market efficiency, using a time-varying approach (see Ito et al., 2014; Ito et al., 2016; Noda, 2016).

In this study, first of all, the AMH is examined in Turkey's Borsa Istanbul stock market by testing the time-varying return predictability of the BIST100 index, which is accepted as the main indicator of this market. The return predictability is investigated via automatic portmanteau and generalized spectral (GS) tests by using daily closing price data from January 1988 to December 2017. Similar to the studies of Kim et al. (2011) and Urquhart \& McGroarty (2016), a two-year moving sub-sample window approach is used to capture the variation of return predictability over time and to determine the periods when the market is predictable and when unpredictable (Charles et al., 2012; Gyamfi, 2018).

Secondly, the AMH test results are utilized for a Hidden Markov model (HMM) application considering periods that present predictable behaviour in order to examine the validity of the predictability for selected determinants of the BIST100 index value. Thereby, an HMM is formed including variables BIST100 index as the observation series and the US Dollars exchange rate, money supply, and consumer price index (CPI) as determinants, in other words, the hidden states. By the solution of evaluation and optimal state sequence problems presented in HMM, estimated values and actual data of the model components are compared and results are interpreted. Although there is an extensive literature of return predictability investigated in the markets of developed countries, there are still a limited number of studies that focus on the emerging markets such as Turkey. Besides, the discrepancy of the results in a variety of studies that tested the EMH for Borsa Istanbul (see Balaban et al., 1996; Özün, 1999; Buguk \& Brorsen, 2003; Kahraman \& Erkan, 2005; Aga \& Kocaman, 2011; Kılıç \& Buğan, 2016) presents an opportunity for the examination of the $\mathrm{AMH}$ as an alternative approach. 
Moreover, financial data series exhibit stochastic features due to the temporal and complex nature of market conditions, changing investment decisions, etc. (Li, 2016). In this context, HMMs have become a well-recognized technique in the financial literature for their ability of modelling and forecasting sequentially varying patterns. Therefore, it can be stated that this paper contributes to the existing literature in two ways: Firstly, by testing AMH, a hypothesis that attracts significant attention in recent years, with two well-known and accepted statistical tests for an emerging market, namely the Borsa Istanbul. Secondly by making use of an effective method, HMMs, in the financial literature in order to utilize and examine the obtained test results of the AMH. The remainder of the paper is organized as follows. The next section presents the recent literature on AMH. Sections 3 and 4 describe the data and methodology while Section 5 reports the results. A brief interpretation of findings, discussions and concluding remarks are given in the last section.

\section{Literature Review}

There is increasing attention to $\mathrm{AMH}$ in the recent financial literature along with strong evidence in favour of the hypothesis. Lim \& Brooks (2006) used portmanteau bicorrelation test statistics with a moving sub-sample window approach in their studies on a total of 50 stock markets. As a result, they stated that the activity in these markets followed a cyclical pattern over time and that the findings were in harmony with the AMH. By using the same methodology, Lim (2007) found out that efficiency varied over time for thirteen markets which is consistent with the AMH. Todea et al. (2009) investigated the moving averages strategy in six markets by using linear and nonlinear tests and according to the results, the efficiency of the markets is not constant, thereby markets show characteristics that are compatible with the AMH. Kim et al. (2011) investigated the return predictability of daily Dow Jones Industrial Average (DJIA) index data for the period 1900 and 2009 by using a moving sub-sample window approach with automatic variance ratio, automatic portmanteau, and GS tests. Results were consistent with the AMH, as they stated that return predictability fluctuates over time and is mostly determined by market conditions, such as market crashes, economic and political crises, etc. Similarly, Alvarez-Ramirez et al. (2012) examined the relative market efficiency in DJIA from 1929 to 2012 by entropy approach. It was stated that the method was suitable for determining the market efficiency level and according to the analysis, DJIA yielded features in accordance with the characteristics specified in the AMH. Butler \& Kazakov (2012) tested the AMH's varying efficiency and cyclic profitability by using experimental data and machine learning methodology. According to the results, it was stated that the method can be used as a predictive tool for the hypothesis. Charles et al. (2012) applied the automatic variance ratio, wild bootstrap automatic variance ratio (WBAVR), GS, and Dominguez-Lobato (DL) tests within a twoyear fixed-length moving sub-sample window approach in order to examine the linear and nonlinear dependencies of the major foreign exchange rates between 1974 and 2009. As a result of the analysis, they found out that the predictability of the exchange rates changed over time according to the market conditions and this was in line with the AMH. Lazăr et al. (2012) investigated the consequences of the global economic and financial crisis in foreign exchange markets of Turkey, Russia, Czechia, Romania, Poland, and Hungary in terms of efficiency by using the GS test. Obtained results indicated intermittent behaviours related to 
linear and nonlinear dependencies rather than continuous developments in efficiency level over time, which is consistent with the AMH. Smith (2012) used variance ratio test for the data of 15 European emerging and three developed markets including the Borsa Istanbul within the moving sub-sample window approach in order to examine the time-varying efficiency of these markets. Changing characteristics of the markets yielded compatible results with the $\mathrm{AMH}$, in addition to the highly efficient feature of the Borsa Istanbul. Lim et al. (2013) investigated the return predictability for DJIA, Standard \& Poor's 500 (S\&P 500), New York Stock Exchange (NYSE) by using wild-bootstrapped automatic variance ratio and automatic portmanteau Box-Pierce tests. According to the second test, the return predictability was accepted for these markets, while the first test yielded negative results. However, it has been explained that the time-varying feature complies with the AMH.

Also, Popović et al. (2013) applied the Runs test within the moving sub-sample approach to the Montenegro MONEX20 index data of 2004-2011 to investigate the market efficiency over time and the result of the analysis confirmed the AMH. Urquhart \& Hudson (2013) studied the validity of the AMH for the stock markets of the US, UK, and Japan with long-term historical data. As a result of the linear tests, it has been determined that all three markets have adaptive characteristics and that the hypothesis generally provides a better explanation of the stock returns compared to the EMH. Verheyden et al. (2013) examined the proposed arguments of the AMH for the data of DJIA, S\&P 500, National Association of Securities Dealers Automated Quotations (NASDAQ), and Belgium's BEL-20 indexes with moving sub-sample windows and variance ratio tests. Although the results confirmed the dynamic and time-varying efficiency, it was also stated that they have encountered activity patterns that contradict the AMH regarding these markets. Zhou \& Lee (2013) handled the Real Estate Investment Trust (REIT) data through automatic variance ratio and automatic portmanteau tests and investigated the predictability of the returns based on market conditions by applying panel data analysis to the regression equation they established. As a result of the analysis, the market has shown features compatible with the $\mathrm{AMH}$ and the main reason for the varying efficiency was mentioned as the development level of the market. Ghazani \& Araghi (2014) conducted a research study with the data of the Tehran stock market (TEPIX) between 1999 and 2013 by using variance ratio, automatic portmanteau, GS, and McLeod-Li tests within moving sub-sample windows. The analysis provided results in accordance with the characteristics specified in the AMH. Hiremath \& Kumari (2014) tested the AMH using linear and nonlinear tests such as Runs, variance ratio, McLeod-Li, ARCH-LM for India's Sensex and Nifty indexes. According to the results, linear tests indicated time-varying efficiency, whereas other tests indicate nonlinear dependence. This was interpreted as the Indian markets were still not adaptive but in the process of evolution. Hiremath \& Narayan (2016) applied generalized Hurst exponent to India's Sensex and Nifty index data between 1991 and 2013 within fixed and moving windows. Obtained results were in accordance with the dynamic characteristic of the AMH and therefore it was stated that these results can be accepted as adaptive features of these markets. Madhavan \& Arrawatia (2016) examined the activities of G8 countries represented by credit default swaps and treasury bills in terms of the AMH and obtained the results using the AR-GARCH filter and rescaled range (R/S) test. According to the analysis, they stated that there are differences between the country activity levels, and these differences that 
change over time mean validation of the hypothesis. Noda (2016) investigated the validity of the AMH for the Japanese stock markets TOPIX and TSE2. According to the results, the market efficiency in both markets has varied over time, hence it was stated that the findings were in harmony with the AMH. Urquhart \& McGroarty (2016) used three bootstrapped version of the variance ratio test in order to test the AMH for S\&P 500, Financial Times Stock Exchange 100 (FTSE100), Japan's NIKKEI225 and Eurozone's EURO STOXX 50 data over the period 1990 and 2014 within a two-year sub-sample window approach. The results indicated predictability fluctuation over time which is consistent with the AMH. Charles et al. (2017) analysed the 1996-2013 data of the Dow Jones Islamic Market and Dow Jones Global indexes by automatic variance ratio and automatic portmanteau tests. As a result, both indexes yielded time-varying predictability and compatible results with the AMH. The Dow Jones Islamic index was tested for AMH in the context of anomalies and efficiency by stochastic dominance and mean-variance approach in the study of Al-Khazali \& Mirzaei (2017) over the period 1996 and 2015. According to the results, the calendar anomalies supported the AMH and it was stated that this hypothesis provided a better explanation regarding the behaviour of the anomalies compared to the EMH.

Additionally, Rahman et al. (2017) examined the data of Bangladesh, India, Pakistan, and Sri-Lanka markets for the period between 1995 and 2013 by WBAVR test and price delay measures. Obtained results yielded time-varying efficiency, which is in line with the AMH. Ertaş \& Özkan (2018) tested the AMH for the Borsa Istanbul BIST100 and S\&P 500 indexes with the monthly data between 1988 and 2018 by examining autocorrelation changes. According to the results, the $\mathrm{AMH}$ has been regarded as a better performer than the EMH in terms of explaining the stock behaviours. Gyamfi (2018) examined the return predictability for Ghanaian stock market indexes GSEALSH and GSEFSII using GS, automatic portmanteau, and WBAVR tests in a moving window from 2011 to 2015. Results indicated higher predictability for GSEALSH compared to GSEFSII and consistent outcomes with the AMH. Khuntia \& Pattanayak (2018) examined AMH for the Bitcoin market and used the 2010-2017 Bitcoin prices as the research data. A moving sub-sample window framework is used with GS and DL tests in order to determine time-varying linear and nonlinear dependence. As a result, they stated that there was an evolving activity in the Bitcoin market which is compatible with the AMH. Boya (2019) investigated the efficiency degree of the French stock market and used a rolling variance ratio approach for the data of the related index (CAC40) over the period 1987-2018. The results presented a pattern switching between periods of efficiency and inefficiency and confirmed the AMH for the French stock market. Ghazani \& Ebrahimi (2019) tested the AMH for OPEC, Brent, and West Texas Intermediate (WTI) oil markets within moving sub-sample windows by using automatic portmanteau and GS tests over the period 2003-2018. The results yielded high efficiency for Brent and WTI, while OPEC presents compatibility with the AMH as the window length increases. Eyüpoğlu \& Eyüpoğlu (2020) tested the AMH for the Borsa Istanbul BIST100 over two periods January 2, 1990 - June 17, 2019 and April 2, 1991 - June 17, 2019 by using both linear and nonlinear tests. According to the results, utilized tests yielded consistent results and confirmed the AMH by presenting periodic return predictability. Similar to the study of Khuntia \& Pattanayak, Khursheed et al. (2020) 
examined AMH for digital currencies such as Bitcoin, Monaro, Litecoin, and Stellermarket over the 2014-2018 period. GS, DL, and automatic portmanteau tests were applied to daily price data to identify time-varying linear and nonlinear dependence. It is stated that digital currency markets supported the AMH as linear and nonlinear dependence varied over time. Kołatka (2020) conducted an analysis by using the daily data of the Polish stock market (WIG) over the period October 1994 - December 2019 by using autocorrelation and Brock, Dechert \& Scheinkman (BDS) tests within moving sub-sample windows. The analysis provided results in favour of the AMH. Lekhal \& El Oubani (2020) examined various aspects of the AMH by using daily data of the Moroccan stock market index MASI with linear (WBAVR, automatic portmanteau, and the TV-AR model) and nonlinear (MacLeod$\mathrm{Li}$ and the momentum returns) tests. The results confirmed the profit opportunities along with return predictability in this market, hence supported the AMH. Obelade \& Muzindutsi (2020) tested the AMH for Tunisian Stock Market (TSE) with daily index return data over the period April 1999 and February 2018 by linear and nonlinear tests. According to the results, high return predictability has been observed for volatile periods and it was stated that the TSE confirms the AMH. Patil \& Rastogi (2020) included a daily dataset of closing prices and the number of trades (volume) of the Indian stock market, Sensex over the period between July 13, 1995, and August 6, 2019, to examine the AMH by utilizing the Multifractal Detrended Fluctuation Analysis (MF-DFA) and the Multifractal Detrended Cross-correlation Analysis (MF-DCCA). According to the obtained results, it is stated that existing chances of arbitrage opportunities supported the AMH for this stock market. Rosini \& Shenai (2020) investigated the AMH and calendar anomalies for London Stock Exchange's FTSE100 and FTSE250 indices over the 2007-2016 period by using autocorrelation, variance ratio, BDS tests, and GARCH models. The results yielded varying efficiency which supports the AMH and also calendar anomalies. Shahid et al. (2020) also examined the AMH and calendar anomalies by associating the Turn-of-Month (TOM) effect to the AMH. In order to do so, the daily return data of Pakistan's PSX index was included in the analysis for the 1996-2015 period. By applying the GARCH methodology, the AMH was specified as more useful than any other approach when explaining the evolving trend for the TOM effect. Tripathi et al. (2020) applied quantile regression methodology to test the AMH in 21 major global market indices. Daily, weekly and monthly data were included in the analysis for the 1998-2018 period. Results yielded positively autocorrelated stock returns at lower quantiles and negatively autocorrelated stock returns at higher quantiles which were considered in line with the features of the AMH.

Also as previously mentioned, hidden Markov models (HMM) are used in various financial applications such as Elliott et al. (1998), Thomas et al. (2002), Rossi \& Gallo (2006), Lin et al. (2009), Langrock et al. (2012), Dias et al. (2015), Dionne \& Hassani, (2015), Nguyen \& Nguyen (2015), Nystrup et al. (2015), Meng et al. (2017), Nystrup et al. (2017), Huang et al. (2019), Zhang et al. (2019). Also, studies that concern Borsa Istanbul, such as Öz (2009) and Dağlıoğlu \& Kiral (2018) are also present in the literature. 


\section{Methodology}

This chapter includes brief explanations of the statistical tests used in this study to determine the time-varying return predictability thereby test the $\mathrm{AMH}$, as well as a short description of the HMMs.

\subsection{Automatic Portmanteau Test}

As one of the widely used tests, the portmanteau test depends on the hypothesis $H_{o}$ : $p_{j}=0$ for all $j=1, \ldots$, p. In other words, the null hypothesis implies that the first $k$ autocorrelations are equal to zero in a time series. Later, Lobato et al. (2001: 190-191) proposed a more robust test statistic which is given below:

$$
\mathrm{Q}^{*}{ }_{\mathrm{k}}=\mathrm{T} \sum_{j=1}^{k} \tilde{p}_{j}^{2}
$$

where the values of $\tilde{p}_{j}^{2}$ were taken as estimators for the autocovariance of stock return order $j$. This is followed by Escanciano \& Lobato's (2009) proposal of an automatic test where $p$ is determined not arbitrary but according to a data-dependent procedure, which can be identified as follows:

$$
\mathrm{AQ}^{*}{ }^{k}=\mathrm{T} \sum_{j=1}^{\tilde{k}} \tilde{p}_{j}^{2}
$$

where the value of $\tilde{p}$ represents the optimal lag order and the automatic portmanteau test statistic (AQ) follows the Chi-squared distribution. If the AQ is calculated greater than 3.84, the null hypothesis of the test which is no return predictability (no return autocorrelation) is rejected at the 5\% level, hence inefficiency is accepted for the related period (Kim et al., 2011: 871).

\subsection{Generalized Spectral Test}

It is stated that as an autocorrelation-based test, the automatic portmanteau test can identify only the linear dependence (Charles et al., 2012: 1612). However, the GS test, proposed by Escanciano \& Velasco (2006) investigates both linear and nonlinear dependencies in a time series as it takes dependence into account for all lags and presents robustness to conditional heteroscedasticity (Gyamfi, 2018: 198). The main idea can be described as transforming the data by an exponential function and taking the spectrum of transformed series into consideration (Zhang, 2013). As a test that involves a wildbootstrapping procedure, if obtained p-value is less than 0.05 , the hypothesis implying no return predictability is rejected at a 5\% level of significance and inefficient market conditions are approved (Kim et al., 2011: 871). (For detailed explanations, see Escanciano \& Velasco (2006), Lazăr et al. (2012), Zhang (2013), and Gyamfi, 2018)).

\subsection{Hidden Markov Models}

The HMM was firstly introduced by Baum and his colleagues in the early 1970s then attracted significant attention in the1980s (Nguyen \& Nguyen, 2015; Y1lmaz \& Can, 2016). 
According to the HMMs, a stochastic process that produces observation sequences is an underlying and hidden stochastic process (Ibe, 2013: 417-419). Therefore in an HMM, a state process that is hidden generates an observation process at time $t\left(S_{t}\right)$; besides, this hidden state fulfils the Markov property as, given the value $S_{t-1}, S_{t}$ depends only on $S_{t-1}$ hence independent from all other states before time $t-1$ (Li, 2016: 6). Basic elements of an HMM are given below (Ching et al., 2013: 202; Ibe, 2013: 419):

- $S=\left\{S_{1}, S_{2}, \ldots, S_{N}\right\}$, a finite set of $N$ hidden states,

- $V=\left\{V_{1}, V_{2}, \ldots, V_{M}\right\}$, a finite set of $M$ possible observation symbols,

- $A=\left\{a_{i j}\right\}$, a set of state transition probability matrix where $a_{i j}$ represents the probability of system going from state $S_{i}$ to state $S_{j}$

- $B=\left\{b_{i}(k)\right.$ represents the probability of observing $V_{k}$ when the system is in state $S_{i}$

- $\pi=\left\{\pi_{i}\right\}$, initial state probabilities that $\pi_{i}$ is the probability of the system starting in state $S_{i}$ and defined as $\pi=\mathrm{P}\left[q_{1}=S_{i}\right], 1 \leq i \leq N$.

Hence for the transition probability matrix $A=\left\{a_{i j}\right\}$ where $\sum_{j=1}^{N} a_{i j}=1, i=1, \ldots, N$ and $a_{i j} \geq 0$, related matrix can be stated as;

$$
a_{i j}=\mathrm{P}\left[q_{t+l}=S_{j} \mid q_{t}=S_{i}\right], 1 \leq i, j \leq N
$$

while transition probabilities do not change over time and independent from observations (Bhar \& Hamori, 2004: 17).

Moreover, observation probabilities $B=\left\{b_{i}(k)\right\}$ can be stated as;

$$
b_{i}(k)=\mathrm{P}\left[O_{T}=V_{k} \mid q_{t}=S_{i}\right]
$$

while $\sum_{k=1}^{M} b_{i}(k)=1, i=1, \ldots, N, k=1, \ldots, M$ and $b_{i}(k) \geq 0$ (Ching et al., 2013: 202).

By considering the number of hidden states $(N)$, the number of possible observation symbols $(M)$ in addition to A, B, and $\pi$, an HMM generates $T$ number of observations $O=$ $\left\{O_{1}, O_{2}, \ldots, O_{T}\right\}$, thereby parameter set of the HMM is simply defined as $\Lambda=\{\mathrm{A}, \mathrm{B}, \pi\}$ (Y1lmaz \& Can, 2016: 119).

Three basic problems of HMMs are given below (Rabiner \& Juang, 1986; Ibe, 2013; Nguyen \& Nguyen, 2015):

1. The evaluation problem focuses on computing the observation probabilities $\mathrm{P}[O \mid$ 1] by using the forward and backward algorithm. Regarding the forward algorithm, a joint probability $a_{t}(i)=\mathrm{P}\left[O=O_{1}, O_{2}, \ldots, O_{t}, q_{t}=S_{i} \mid \Lambda\right]$ must be defined and calculated repeatedly. The sum of these values yields the observation probabilities as follows:

$\mathrm{P}[\mathrm{O} \mid \Lambda]=\sum_{i=1}^{N} a_{t}(i)$

Similarly, a conditional probability: 


$$
\beta_{\mathrm{t}}(\mathrm{i})=\mathrm{P}\left[\mathrm{O}_{\mathrm{t}+1}, \mathrm{O}_{\mathrm{t}+2}, \ldots, \mathrm{O}_{\mathrm{T}}\left|\mathrm{q}_{\mathrm{t}}=\mathrm{S}_{\mathrm{i}}\right| \Lambda\right]
$$

is defined for the backward algorithm and this equation is calculated backwards starting from $t=T-1$, hence the total probability is obtained as follows:

$$
\mathrm{P}[\mathrm{O} \mid \Lambda]=\sum_{i=1}^{N} \beta_{1}(i) a_{1}(i)=\sum_{i=1}^{N} \beta_{1}(i) \pi_{1} b_{1}\left(O_{1}\right)
$$

2. The optimal state sequence (decoding) problem is concerned with calculating the most likely sequence of hidden states which will generate the given observation sequence by using the Viterbi algorithm. First of all, a $\delta_{t}(i)$ variable is defined as given below:

$$
\delta_{t}(i)=\underset{q_{1}, q_{2}, \ldots, q_{t-1}}{\max } \mathrm{P}\left[\mathrm{q}_{1}, \mathrm{q}_{2}, \ldots, \mathrm{q}_{\mathrm{t}-1}, \mathrm{q}_{\mathrm{t}}=\mathrm{S}_{\mathrm{i}}, \mathrm{O}_{1}, \mathrm{O}_{2}, \ldots, \mathrm{O}_{\mathrm{t}}, \mathrm{q}_{\mathrm{t}} \mid \Lambda\right]
$$

and by induction:

$$
\delta_{t+1}(i)=\max _{i}\left[\delta_{t}(i) a_{i j}\right] b_{j}\left(O_{t+1}\right)
$$

is obtained. Then the most likely state $q^{*}{ }_{T}$ will be chosen by the given formula below:

$$
\mathrm{q}^{*} \mathrm{~T}=\underset{1 \leq i \leq N}{\operatorname{argmax}}\left[\delta_{T}(i)\right]
$$

3. The learning problem utilizes the Baum-Welch algorithm in order to optimize the $\{\mathrm{A}, \mathrm{B}, \pi\}$ parameters by maximizing the observation sequence probabilities. In order to represent how to calculate the parameters, a new variable $\xi_{t}(i, j)$ must be defined as given below:

$\xi_{t}(i, j)=\mathrm{P}\left[q_{t}=S_{i}, q_{t+1}=S_{j} \mid O, \Lambda\right]$

Also, a probability variable $\gamma_{t}(i)$ is defined as follows:

$\gamma_{t}(i)=a_{t}(i) \beta_{t}(i) / \mathrm{P}[O \mid \Lambda]$

Then, variable $\xi_{t}(i, j)$ can be stated as given below:

$$
\xi_{t}(i, j)=\mathrm{P}\left[\mathrm{q}_{\mathrm{t}}=\mathrm{S}_{\mathrm{i}}, \mathrm{q}_{\mathrm{t}+1}=\mathrm{S}_{\mathrm{j}} \mid \mathrm{O}, \Lambda\right]=\frac{a_{t}(i) a_{i j} b_{j}\left(O_{t+1}\right) \beta_{t+1}(j)}{P[O \mid \Lambda]}
$$

hence;

$$
\gamma_{t}(i)=\sum_{j=1}^{N} \xi_{t}(i, j)
$$

can be defined. This summation will provide new parameters; the expected number of transitions from state $S_{i}$ to $S_{j}, \bar{a}_{i j}$ and $\bar{b}_{j}(k)$, the ratio of the number of times when the system is in state $S_{j}$ and observing symbol is $v_{k}$ to the expected number of times that the system is in state $S_{j}$. Therefore, new parameters can be defined as given below: 


$$
\bar{a}_{i j}=\frac{\sum_{t=1}^{T-1} \xi_{t}(i, j)}{\sum_{t=1}^{T-1} \gamma_{t}(j)}, \bar{b}_{j}(k)=\frac{\sum_{t=1, v_{k}}^{T} \gamma_{t}(j)}{\sum_{t=1}^{T} \gamma_{t}(j)}
$$

Finally, the re-estimated model can be stated as $\bar{\Lambda}=\{\bar{A}, \bar{B}, \bar{\pi}\}$.

\section{Data}

In the first section of this study, daily closing prices of the BIST100 index were used in order to examine the AMH by testing the time-varying return predictability. The data were obtained from The Central Bank of the Republic of Turkey Electronic Data Delivery System and range from 4 January 1988 to 18 December 2017. The daily closing prices of the stock exchange are transformed into returns by the formula given below in which the natural logarithm of the index at time $t$ is $\ln \left(P_{t}\right)$ :

$$
\mathrm{r}_{\mathrm{t}}=\ln \left(\mathrm{P}_{\mathrm{t}}\right)-\ln \left(\mathrm{P}_{\mathrm{t}-1}\right)
$$

Given below, Graph 1 presents the plot of the daily index and log returns:

\section{Graph: 1}

\section{Time Plot of BIST100 Daily Index and Log Returns}

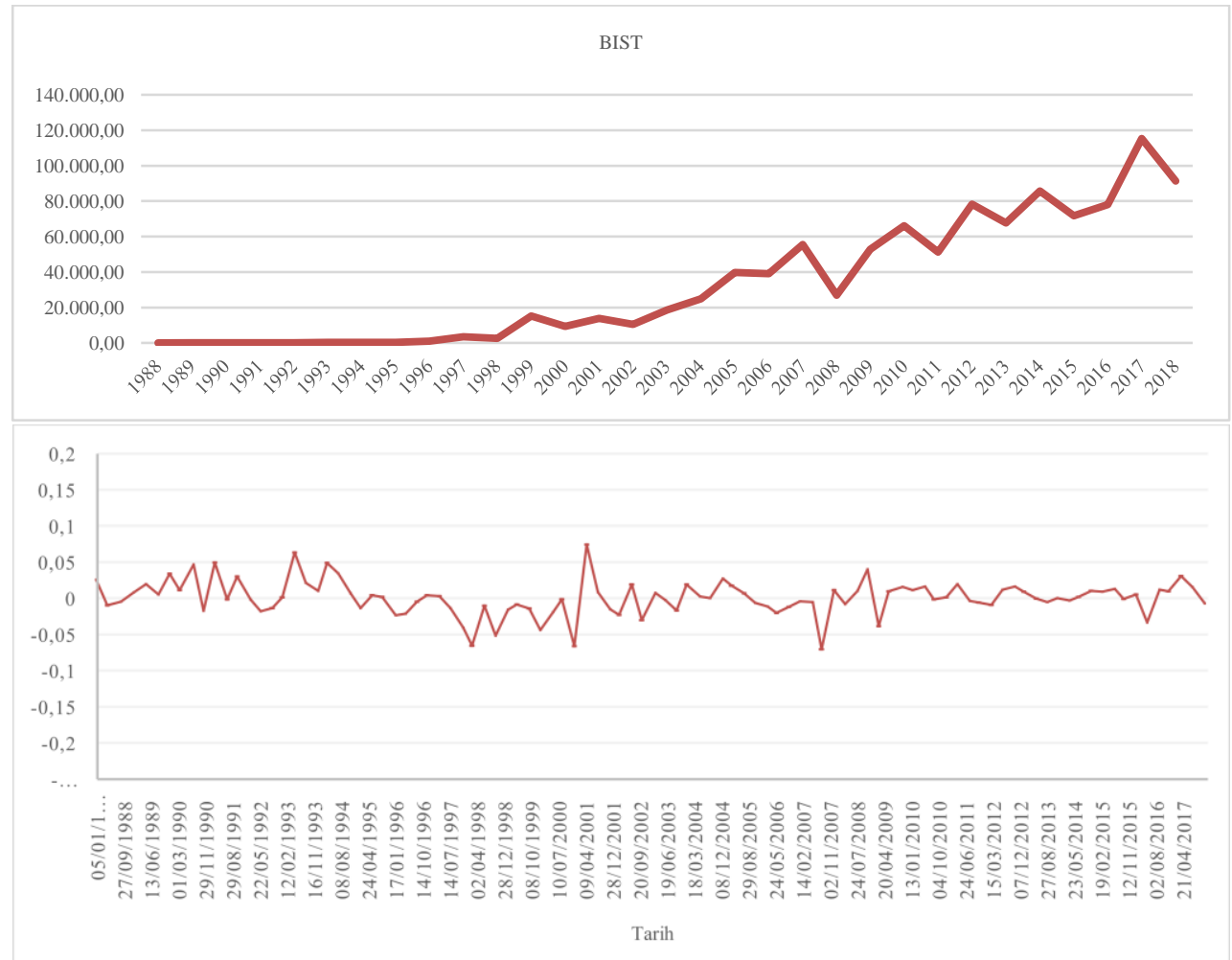

Source: The Central Bank of the Republic of Turkey Electronic Data Delivery System. 
According to Graph 1, the market is bullish until 2008, however, BIST100 index suffers a sharp decline around 2008 due to the global crisis. This is followed by a bullish period until 2011 and then presents a volatile pattern since then. The descriptive statistics of the daily returns are given in Table 1:

Table: 1

Descriptive Statistics of Daily Returns of the BIST100 Index

\begin{tabular}{cc}
\hline Observations & 7485 \\
Mean & 0.001293 \\
Median & 0.001148 \\
Std. Deviation & 0.025514 \\
Skewness & -0.046280 \\
Kurtosis & 7.387619 \\
Jarque-Bera & 6006.641 \\
\hline
\end{tabular}

According to Table 1, the returns indicate negative skewness and a high kurtosis value presents leptokurtic distribution. Moreover, the Jarque-Bera test statistic indicates the non-normal nature of the returns at the $1 \%$ level. In accordance with the explanation of Gyamfi (2018), the data must include nonlinear patterns in order to apply the GS test. Therefore, a BDS test was applied and according to the result, the test provided p-values less than 0.05 , which verifies the nonlinearity.

\section{Empirical Results}

\subsection{Time-Varying Return Predictability}

In order to evaluate the time-varying return predictability, a moving window approach along with the automatic portmanteau and GS tests was used in this study. Graph 2 provides the AQ values and a dotted line corresponds to a $5 \%$ critical value of 3.84 .

Graph: 2

\section{Automatic Portmanteau Test Statistics}

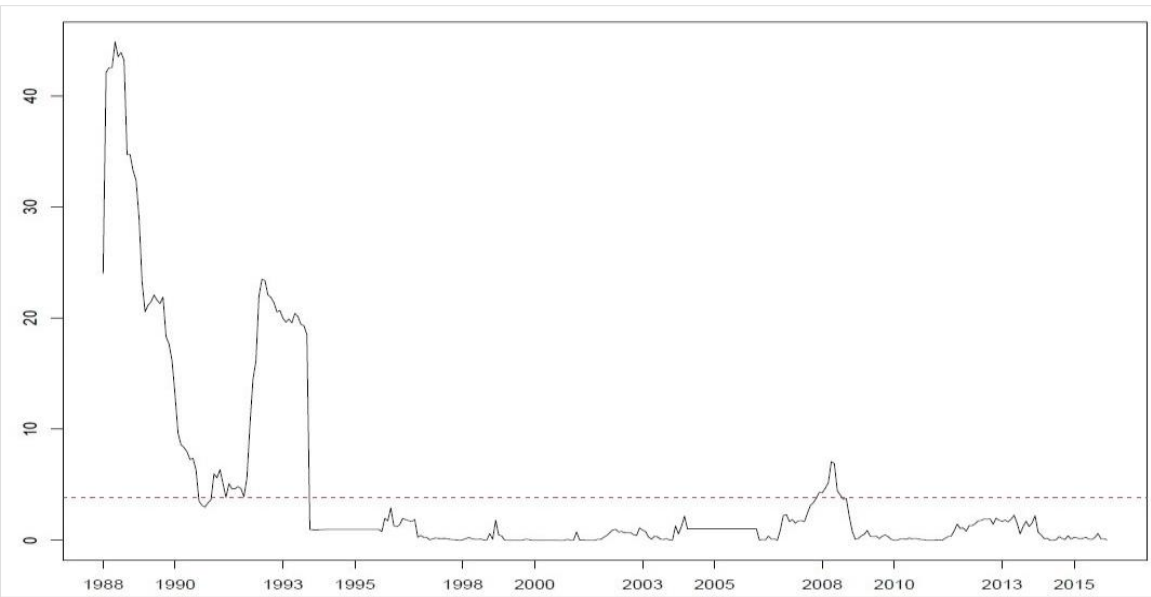


According to Graph 2, the result of the automatic portmanteau test can be considered significant for the periods in which the AQ values are over the dotted critical value line. Thereby, it can be stated that the test statistics show a high degree of return predictability and inefficient market conditions for the period 1988-1990 and around 1993 except for a short period around 1991. After a dramatic decline in the test statistics after 1993, the test provides statistically insignificant results, which indicates unpredictable stock return features and efficiency in the market for a long time until 2008. Then, statistically significant test statistics suggest the predictable nature of returns and inefficient market conditions around 2008. Finally, from late 2008 to the end of the sample period, the unpredictable behaviour of the stock returns and inefficiency carries on. Therefore, according to the automatic portmanteau test results, it can be clearly stated a time-varying behaviour of efficiency is evident with three different periods of predictability for the BIST100 index and results support the AMH for Borsa Istanbul. The results of the GS test are given below in Graph 3.

\section{Graph: 3}

\section{P-values of the Generalized Spectral (GS) Test}

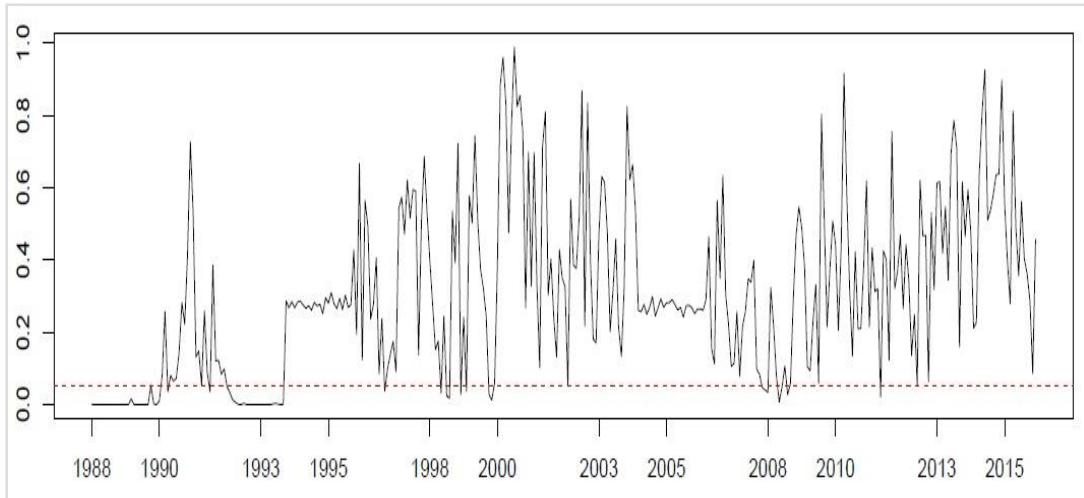

Graph 3 presents p-values of GS test for daily data of BIST100 index and the dotted line represents the $\mathrm{p}$-value 0.05 . The result of the GS test can be considered as significant for the periods in which the test values are below the dotted p-value line. Similar to the results of the automatic portmanteau test, no return predictability hypothesis is rejected at the beginning period of the data. According to the figure, there is evidence of return predictability from 1988 to the late 1990s. After a period of no return predictability with calculated p-values greater than 0.05, the data presents significant p-values around 1993, which means an inefficient feature for the market. After five years with no significant $\mathrm{p}$ values indicating no return predictability, short terms of return predictability can be seen between 1998 and 2000. Similar to the automatic portmanteau test results, stock returns were unpredictable, traders could not predict future prices based on the past asset prices, and efficient market conditions were experienced until 2008. Again, with a similarity to the previous test results, the year 2008 presents a short-term of return predictability with pvalues lower than 0.05 . From 2008 to the end of the sample period, the GS test p-values are 
statistically insignificant, which means failure to reject the hypothesis implying no return predictability and duration of efficiency for Borsa Istanbul.

When compared to the related previous studies of Ertaş \& Özkan (2018) and Eyüpoğlu \& Eyüpoğlu (2020) in which the AMH is tested for similar periods, it can be stated that there is a consensus on the periodic return predictability in the Borsa Istanbul. Therefore, the BIST100 provided strong evidence for the AMH as the inferential outcomes of both automatic portmanteau and GS tests are obtained as largely consistent with each other.

\subsection{HMM Application}

After examining the AMH for the Borsa Istanbul, the test results are utilized for an HMM application regarding the periods that present predictability in order to examine the validity of this outcome for selected determinants of the BIST100 index value. Firstly, an HMM similar to the model used by Öz (2009) is formed also in accordance with a literature review and aggregated opinions of experts. The model includes BIST100 index as the observation series and the US Dollars exchange rate, money supply, and consumer price index (CPI) variables as hidden states. Since the automatic portmanteau test result mostly covers the predictable periods obtained in the GS test, periods with predictability were determined as of February 1991 - September 1993 and February 2008 - October 2008 by considering the result of the automatic portmanteau test and data accessibility. As previously stated, the last two months of these periods were estimated by the solutions of evaluation and optimal state sequence problems and compared with the actual values. The learning problem and its solution are not included in the analysis.

At the beginning of the application, change ratio series (CRS) were acquired for all observation series and hidden states by the formula given below:

$$
C R S=\text { (current month's value - previous month's value) } x 100 / \text { previous month's value }
$$

Then, each series were classified into two or four groups according to the arithmetic means of months with the increase (positive change values, if any) and decrease (negative change values, if any) and a symbol is assigned for each group.

Considering the first period February 1991 - September 1993, the arithmetic mean of positive values of change ratio series of BIST100 observation series was 14.55919 and the arithmetic mean of negative values was -8.37184 . In accordance with these calculations, four groups and assigned symbols are given in Table 2:

\section{Table: 2 \\ Assigned Symbols and Groups of BIST100 for the Period of February 1991 - September 1993}

\begin{tabular}{ccc}
\hline Change Ratio $(\mathrm{CR})$ & Symbol \\
\hline CR $\geq 14.55919$ & A1 \\
A2 & A $2<14.55919$ & A3 \\
A $4.37184<$ CR $<0$ & CR $\leq-8.37184$ & A \\
\hline
\end{tabular}


According to Table 2, the symbols, namely, A1(above positive mean value) and A2 (below positive mean value) refer to positive changes in BIST100 over this period, whereas A3 (above negative mean value) and A4 (below negative mean value) refer to negative changes. Therefore, the assigned symbol for change ratios higher than 14.55919 will be A1; and $\mathrm{A} 2$ for the ratios ranging between 0 and 14.55919 which will both considered as the increase. The assigned symbol for change ratios lower than 0 and bigger than -8.37184 will be A3; and A4 for the ratios lower than -8.37184 which will both considered as the decrease in the change ratios.

Regarding the hidden states, the US Dollars exchange rate over the period between February 1991 - September 1993 provided the arithmetic mean of positive values as 4.422869 and no negative values of change were obtained. Symbols were assigned accordingly as B1 (above positive mean value) and B2 (below positive mean value). Concerning money supply, the arithmetic mean of positive values was obtained as 7.172406 and -5.59508 for negative values. Therefore, $\mathrm{C} 1$ (above positive mean value), C2 (below positive mean value), C3 (above negative mean value), and C4 (below negative mean value) symbols were assigned. Finally, the CPI yielded arithmetic mean for positive values as 4.390244, and no negative values of change were obtained similar to the first hidden state. Thereby, D1 (above positive mean value) and D2 (below positive mean value) symbols were assigned for this hidden state. In this context, arithmetic means and assigned symbols are given in Table 3:

Table: 3

\section{Assigned Symbols and Groups of Hidden States for the Period of February 1991 - September 1993}

\begin{tabular}{cc}
\hline Change Ratio $(\mathrm{CR})$ & Symbol \\
\hline $\mathrm{CR} \geq 4.422869$ & $\mathrm{~B} 1$ \\
$0 \leq \mathrm{CR}<4.422869$ & $\mathrm{~B} 2$ \\
\hline Change Ratio $(\mathrm{CR})$ & Symbol \\
\hline $\mathrm{CR} \geq 7.172406$ & $\mathrm{C} 1$ \\
$\mathrm{C} 2$ & $\mathrm{C} 3$ \\
\hline $\mathrm{CR}<7.172406$ & $\mathrm{C} 4$ \\
\hline $\mathrm{CR} \leq-5.59508$ & Symbol \\
\hline Change Ratio $(\mathrm{CR})$ & $\mathrm{D} 1$ \\
$\mathrm{CR} \geq 4.390244$ & $\mathrm{D} 2$ \\
\hline
\end{tabular}

According to Table 3, symbols B1, B2, C1, C2, D1, and D2 refer to positive changes (increase) in all hidden states for this period, whereas $\mathrm{C} 3$ and $\mathrm{C} 4$ refer to negative changes (decrease) in the money supply. It can be stated that there are no negative changes in the US Dollars exchange rate and the CPI for this period.

The given symbols refer to the sub-states and transitions between these sub-states are possible; however, a transition from a set of sub-states to another is not. Thereby, Öz (2009) and Yilmaz (2015) recommended a set of combinations of these sub-states with new symbols in order to ensure these transitions. For instance, the first new sub-state includes B1, C1, D1 sub-states, and the assigned symbol is X1. In accordance with this, the second new sub-state $\mathrm{X} 2$ consists of B1, C1, and D2, and so on, up to X64 which includes B4, C4, and D4. 
Therefore, these new sets of sub-states present new hidden states in accordance with the combinations.

By considering the elements of an HMM, it can be stated that sets of hidden states and observations $(S$ and $V$ ) are obtained. Although a 64-element new hidden state cluster was formed, the handled period did not bring about all possible combinations, but only twelve of them. Thereby, a $12 \times 12$ sized state transition probability matrix $(A)$ has been generated. Related matrix is given in Table 4 below:

Table: 4

State Transition Probability Matrix for the Period of February 1991 - September 1993

\begin{tabular}{|c|c|c|c|c|c|c|c|c|c|c|c|c|}
\hline & $\mathrm{X} 2$ & $\mathrm{X} 5$ & X6 & $\mathrm{X} 9$ & $\mathrm{X} 10$ & $\mathrm{X} 13$ & $\mathrm{X} 17$ & $\mathrm{X} 18$ & $\mathrm{X} 21$ & $\mathrm{X} 22$ & $\mathrm{X} 25$ & X29 \\
\hline $\mathrm{X} 2$ & 0 & 0 & 0 & 0 & 0 & 0 & 0 & 0 & 0 & 1 & 0 & 0 \\
\hline $\mathrm{X} 5$ & 0 & 0.25 & 0.25 & 0 & 0.25 & 0 & 0 & 0.25 & 0 & 0 & 0 & 0 \\
\hline X6 & 0 & 0 & 0.5 & 0 & 0 & 0 & 0 & 0.5 & 0 & 0 & 0 & 0 \\
\hline $\mathrm{X} 9$ & 0 & 0 & 0 & 0 & 1 & 0 & 0 & 0 & 0 & 0 & 0 & 0 \\
\hline $\mathrm{X} 10$ & 0.333333 & 0.666667 & 0 & 0 & 0 & 0 & 0 & 0 & 0 & 0 & 0 & 0 \\
\hline $\mathrm{X} 13$ & 0 & 1 & 0 & 0 & 0 & 0 & 0 & 0 & 0 & 0 & 0 & 0 \\
\hline X17 & 0 & 0 & 0 & 0 & 0.5 & 0 & 0 & 0 & 0.5 & 0 & 0 & 0 \\
\hline X18 & 0 & 0 & 0 & 0 & 0 & 0.2 & 0 & 0 & 0.4 & 0.2 & 0 & 0.2 \\
\hline $\mathrm{X} 21$ & 0 & 0.25 & 0 & 0 & 0 & 0 & 0 & 0 & 0.25 & 0.25 & 0.25 & 0 \\
\hline X22 & 0 & 0 & 0 & 0 & 0 & 0 & 0.5 & 0.25 & 0 & 0.25 & 0 & 0 \\
\hline $\mathrm{X} 25$ & 0 & 0 & 0 & 0 & 0 & 0 & 0 & 1 & 0 & 0 & 0 & 0 \\
\hline $\mathrm{X} 29$ & 0 & 0 & 0 & 0 & 0 & 0 & 0 & 1 & 0 & 0 & 0 & 0 \\
\hline
\end{tabular}

In accordance with Table 4 and the Markovian assumption that each month's state is dependent on the previous month's, it can be stated that there is a $100 \%$ probability that hidden state X2 will be followed by hidden state X22 as the value in the matrix is 1; similarly, after hidden state X5, there is a $25 \%$ probability each for the next hidden state will appear as X5, X6, X10 or X18 and the following items can be interpreted accordingly. This is followed by forming the observation probabilities matrix $(B)$. This matrix is generated with regard to the states of transition probabilities matrix and one of the observation symbols (A1, A2, A3, or A4) comes up accordingly. This matrix is given below:

Table: 5

Observation Probabilities Matrix for the Period of February 1991 - September 1993

\begin{tabular}{ccccc}
\hline & & & $\mathrm{A} 3$ & $\mathrm{~A} 4$ \\
X2 & $\mathrm{A} 1$ & $\mathrm{~A} 2$ & 1 & 0 \\
X5 & 0 & 0 & 0.4 & 0.4 \\
X6 & 0 & 0.2 & 0 & 0.5 \\
X9 & 0 & 0.5 & 0 & 0.333333 \\
X10 & 1 & 0 & 0.333333 & 0 \\
X13 & 0.333333 & 0 & 0 & 0.5 \\
X17 & 0 & 0 & 0.2 & 0 \\
X18 & 0.5 & 0.4 & 0.25 & 0.25 \\
X21 & 0.4 & 0.5 & 0.25 & 0 \\
X22 & 0.5 & 0.25 & 0 & 0 \\
X25 & 1 & 0 & 0 & 0 \\
X29 & 0 & 1 & & 0 \\
\hline
\end{tabular}

According to Table 5, there is a $100 \%$ probability that hidden state $\mathrm{X} 2$ will generate observation A3 as the probability value is 1 for this observation; whereas hidden state X5 will generate observation A2 with $20 \%$, A3 with $40 \%$, and A4 with $40 \%$ probabilities and the following items can also be interpreted accordingly. As for the last element of the basic 
HMM, initial state probabilities $(\pi)$ are included as equal values since there is no dominance among hidden states. This is followed by the solution of the evaluation problem for the last two months of the handled period (August 1993 and September 1993) in order to compare obtained values with actual data. Observation probability forecasts are given in Table 6 below:

Table: 6

Observation Probability Forecast for August 1993

\begin{tabular}{cc}
\hline Symbol & Probability \\
\hline A1 & $\mathbf{0 . 5}$ \\
A2 & 0.25 \\
A3 & 0.25 \\
A4 & 0 \\
\hline
\end{tabular}

According to Table 6, the observation with the highest probability for August 1993 is A1 (above positive mean value) which yields $50 \%$ probability, and this is followed by A2 (below positive mean value) and A3 (above negative mean value) with $25 \%$ probabilities each. It can be stated that the prediction of a positive change (A1 and A2) for this period has the highest probability. When compared to the actual data which is A2, the forecast can be considered as almost consistent. Since the probability of A4 (below negative mean value) is zero, this observation is not included in the calculations of possible outcomes of the August 1993 - September 1993 period. Obtained results are given as follows:

Table: 7

Observation Probability Forecast for August 1993 - September 1993

\begin{tabular}{lclc}
\hline Symbol & Probability & Symbol & Probability \\
\hline A1, A1 & $\mathbf{0 . 4 7 5}$ & A2, A3 & 0.1125 \\
A1, A2 & 0.1625 & A2, A4 & 0.25 \\
A1, A3 & 0.1125 & A3, A1 & 0.475 \\
A1, A4 & 0.25 & A3, A2 & 0.1625 \\
A2, A1 & 0.475 & A3, A3 & 0.1125 \\
A2, A2 & 0.1625 & A3, A4 & 0.25 \\
\hline
\end{tabular}

According to Table 7, the highest probabilities belong to sequences of A1, A1; A2, A1 and A3, A1 for August 1993 - September 1993 with the value of 0.475. Since the actual data for September 1993 is A1, it can be stated that all possible sequences presented consistent results which forecast above positive mean value.

In continuation, the solutions of the optimal state sequence (decoding) problem for the given period is handled. As this procedure provides the most likely sequence of hidden states which generate the given observation sequence, it was found that the hidden state that yields A1 for August 1993 was X25. This hidden state includes positive changes for the US Dollars exchange rate and CPI, however negative changes for the money supply (B2, C3, D1). According to the actual data, the hidden state was X22, hence positive changes for all sub-states were observed (B2, C2, D2). Therefore, it can be stated that except for the money supply, forecasts that predict positive change are almost consistent. Regarding the August 1993 - September 1993 period, forecast results were given in Table 8 below: 
Table: 8

Hidden State Forecast for August 1993 - September 1993

\begin{tabular}{lccccc}
\hline Symbol & Hidden State Forecast & Sub-states & Symbol & Hidden State Forecast & Sub-states \\
\hline A1, A1 & X25, X22 & B2, C3, D1 - B2, C2, D2 & A2, A3 & X25, X25 & B2, C3, D1 - B2, C3, D1 \\
A1, A2 & X25, X17 & B2, C3, D1 - B2, C1, D1 & A2, A4 & X25, X22 & B2, C3, D1 - B2, C2, D2 \\
A1, A3 & X25, X25 & B2, C3, D1 - B2, C3, D1 & A3, A1 & X25, X22 & B2, C3, D1 - B2, C2, D2 \\
A1, A4 & X25, X22 & B2, C3, D1 - B2, C2, D2 & A3, A2 & X25, X17 & B2, C3, D1 - B2, C1, D1 \\
A2, A1 & X25, X22 & B2, C3, D1 - B2, C2, D2 & A3, A3 & X25, X25 & B2, C3, D1 - B2, C3, D1 \\
A2, A2 & X25, X17 & B2, C3, D1 - B2, C1, D1 & A3, A4 & X25, X22 & B2, C3, D1 - B2, C2, D2 \\
\hline
\end{tabular}

When compared to the values given in Table 8 above, it can be stated that the forecast X22 for September 1993 can be considered highly consistent as it predicts below the positive mean value for all sub-states (B2, C2, D2). Hence the actual observation of this period consisted of positive changes regarding the actual values of sub-states (B2, C2, D1).

Considering the second period, February 2008 - October 2008, the arithmetic mean of positive values of change ratio series of BIST100 observation series was 6.862312 and the arithmetic mean of negative values was -8.9751 . In accordance with these calculations, four groups and assigned symbols are given in Table 9:

\section{Table: 9}

\section{Assigned Symbols and Groups of BIST100 for the Period of February 2008 - October} 2008

\begin{tabular}{ccc}
\hline Change Ratio (CR) & Symbol \\
\hline $\mathrm{CR} \geq 6.862312$ & $\mathrm{~A} 1$ \\
$0 \leq \mathrm{CR}<6.862312$ & $\mathrm{~A} 2$ \\
$\mathrm{~A} 3$ \\
$\mathrm{-} .9751<\mathrm{CR}<0$ & $\mathrm{~A} 4$ \\
\hline
\end{tabular}

According to Table 9, the symbols, namely, A1 (above positive mean value) and A2 (below positive mean value) refer to positive changes in the BIST100 over this period, whereas A3 (above negative mean value) and A4 (below negative mean value) refer to negative changes. Therefore, the assigned symbol for change ratios higher than 6.862312 will be A1; and A 2 for the ratios between 0 and 6.862312 which will both considered as the increase. Hence, A3 and A4 will be considered as the decrease in the change ratios.

Regarding the hidden states, the US Dollars exchange rate over the period between February 2008 - October 2008 provided the arithmetic mean of positive values as 6.971529 and -2.47719 for negative values. Symbols were assigned accordingly as B1 (above positive mean value) and B2 (below positive mean value), B3 (above negative mean value), and B4 (below negative mean value). Concerning money supply, the arithmetic mean of positive values was obtained as 4.908061 and -1.6306 for negative values. Therefore, $\mathrm{C} 1$ (above positive mean value), C2 (below positive mean value), C3 (above negative mean value), and $\mathrm{C} 4$ (below negative mean value) symbols were assigned. Finally, the CPI yielded arithmetic mean for positive values as 1.292083 and -0.29948 for negative values. Thereby, D1 (above positive mean value), D2 (below positive mean value), D3 (above negative mean value), and D4 (below negative mean value) symbols were assigned for this hidden state. In this context, arithmetic means and assigned symbols are given in Table 10: 
Table: 10

Assigned Symbols and Groups of Hidden States for the Period of February 2008 October 2008

\begin{tabular}{cc}
\hline Change Ratio (CR) & Symbol \\
\hline $\mathrm{CR} \geq 6.971529$ & $\mathrm{~B} 1$ \\
$0 \leq \mathrm{CR}<6.971529$ & $\mathrm{~B} 2$ \\
$\mathrm{-} .47719<\mathrm{CR}<0$ & $\mathrm{~B} 3$ \\
$\mathrm{CR} \leq-2.47719$ & $\mathrm{~B} 4$ \\
\hline $\mathrm{Change}$ Ratio $(\mathrm{CR})$ & $\mathrm{C} 1$ \\
$\mathrm{CR} \geq 4.908061$ & $\mathrm{C} 2$ \\
$0 \leq \mathrm{CR}<4.908061$ & $\mathrm{C} 3$ \\
\hline$-1.6306<\mathrm{CR}<0$ & $\mathrm{C} 4$ \\
\hline $\mathrm{CR} \leq-1.6306$ & Symbol \\
\hline $\mathrm{Change}$ Ratio $(\mathrm{CR})$ & $\mathrm{D} 1$ \\
$\mathrm{CR} \geq 1.292083$ & $\mathrm{D} 2$ \\
$\mathrm{C} 3 \mathrm{CR}<1.292083$ & $\mathrm{C} 4$ \\
\hline
\end{tabular}

According to Table 10, symbols B1, B2, C1, C2, D1, and D2 refer to positive changes in hidden states for this period, whereas B3, B4, C3, C4, and D3, D4 refer to negative changes. It can be stated that all hidden states faced negative changes in this period. Similar to the previous period's application, new symbols with $\mathrm{X}$ that include combinations of these sub-states as new hidden states are used for this period. As this period did not bring about all possible combinations either, a $6 \times 6$ sized state transition probability matrix $(A)$ has been generated. Related matrix is given in Table 11 below:

Table: 11

State Transition Probability Matrix for the Period of February 2008 - October 2008

\begin{tabular}{cccccc}
\hline & X18 & X21 & X40 & X42 & 0 \\
X18 & 0 & 1 & 0 & 0 & 0 \\
X21 & 0 & 1 & 0 & 1 & 0 \\
X40 & 0 & 0 & 0 & 0 & 0 \\
X42 & 0 & 0 & 0 & 0 & 0 \\
X61 & 0 & 0 & 1 & 0 & 0 \\
X63 & 1 & 0 & 0 & 0 & 0 \\
\hline
\end{tabular}

According to Table 11, it can be stated that there is a $100 \%$ probability of hidden state X18 will be followed by hidden state X21 as the value in the matrix is 1; similarly, after hidden state $\mathrm{X} 21$, there is a $100 \%$ probability that the next hidden state will appear as $\mathrm{X} 21$ and the following items can be interpreted accordingly. This is followed by forming the observation probabilities matrix $(B)$ which is given below in Table 12:

Table: 12

Observation Probabilities Matrix for the Period between February 2008 - October 2008

\begin{tabular}{lcccc}
\hline & A1 & A2 & A3 & A4 \\
X18 & 0 & 0 & 0,5 & 0,5 \\
X21 & 0 & 0 & 1 & 0 \\
X40 & 0 & 0 & 1 & 0 \\
X42 & 0 & 0 & 1 & 0 \\
X61 & 0 & 0 & 0 & 0 \\
X63 & 1 & 0 & 0 & 0 \\
\hline
\end{tabular}


According to Table 12, there is a $50 \%$ probability each that hidden state $\mathrm{X} 2$ will generate observations $\mathrm{A} 3$ and $\mathrm{A} 4$ as the related value in the matrix is 0,5 ; whereas hidden state X21 will generate only the observation A4 because of the probability value 1 and the rest of the items can be interpreted in the same way. Similar to the first application, initial state probabilities $(\pi)$ are included as equal values since there is no dominance among hidden states.

In continuation, the evaluation problem is solved for the last two months of the handled period (September 2008 and October 2008) in order to compare obtained values with actual data. Observation probability forecasts are given in Table 13 below:

Table: 13

Observation Probability Forecast for September 2008

\begin{tabular}{cc}
\hline Symbol & Probability \\
\hline A1 & 0 \\
A2 & 0 \\
A3 & 0 \\
A4 & 1 \\
\hline
\end{tabular}

According to Table 13, with a 100\% probability, the observation for September 2008 is A4 (below negative mean value). When compared to the actual data which is A4, it can be stated that the forecast is consistent with the prediction of a decrease below the negative mean value. Since there is zero probability for A1, A2, and A3 to happen, these observations are not included in the calculations of possible outcomes of the September 2008 - October 2008 period. Obtained results are given as follows in Table 14:

Table: 14

Observation Probability Forecast for September 2008 - October 2008

\begin{tabular}{cc}
\hline Symbol & Probability \\
\hline A4, A1 & 0 \\
A4, A2 & 0 \\
A4, A3 & 0 \\
A4, A4 & $\mathbf{1}$ \\
\hline
\end{tabular}

According to Table 14, there is a 100\% probability that September 2008's observation A4 will be followed by a below negative mean value, hence A4 again in October 2008. Because of the fact that a decrease below the negative mean value was observed in reality, this forecast is also considered as accurate. Regarding the solution of the optimal state sequence (decoding) problem the hidden state that yields A4 for September 2008 was $\mathrm{X} 21$. This hidden state includes positive changes for all sub-states (B2, C2, D1). According to the actual data, the hidden state was X18, hence positive changes for all sub-states were observed (B2, C1, D2). Therefore, it can be stated that forecasts are almost consistent with the predictions of positive changes. Forecast results were given for the September 2008 October 2008 period in Table 15 below:

Table: 15

Hidden State Forecast for September 2008 - October 2008

\begin{tabular}{ccc}
\hline Symbol & Hidden State Forecast & Sub-states \\
\hline $\mathbf{A 4 ,}$ A4 & X21, X21 & B2, C2, D1 - B2, C2, D1 \\
\hline
\end{tabular}


According to Table 15 above, the hidden state sequence of October 2008 should be the same as September 2008, namely B2, C2, D1. When the actual data and obtained results are compared, performed forecast can be regarded as almost consistent since the actual data of October 2008 were B1, C4, D1. Therefore, it can be stated that forecasts of an increase in US Dollars exchange rate and CPI matches with the actual data, however, an inconsistent prediction regarding the money supply sub-state is observed. In conclusion, obtained findings imply that apart from small deviations, the utilized HMM model presented mostly consistent results with the actual data of handled periods. Thereby, it can be stated that predictability is mostly evident regarding these periods also for the determinants that affect the BIST100 index.

\section{Discussion \& Conclusions}

In this paper, firstly the AMH is investigated in Turkey's Borsa Istanbul stock market by testing the time-varying return predictability over a given period. The analysis was conducted by using daily closing price data of the BIST100 index between January 1988 and December 2017, which is accepted as the main indicator of this market. In order to capture the linear dependence in stock returns, the automatic portmanteau test, which is a frequently used tool in the literature, is used. Also, to detect a probable nonlinear dependence among these returns, the GS test has been applied. Both of the tests have been implemented by using moving sub-sample windows, similar to the studies of Kim et al. (2011), Charles et al. (2012), Urquhart \& McGroarty (2016), and Gyamfi (2018).

Secondly, obtained results of the AMH examination were used in an HMM application in order to investigate the validity of the predictability for selected determinants of the BIST100 index value. Since financial markets are mostly volatile and dynamic by nature, HMMs attract significant attention from researchers as a feasible method of prediction because of their convenience for modelling dynamic systems. In accordance with the model used by Öz (2009) and also with regard to a literature review and aggregated opinions of experts and scholars, an HMM is established. The model included monthly data of the BIST100 index as the observation series, while US Dollars exchange rate, money supply, and consumer price index (CPI) variables are added as the hidden states that have influence on the index. After estimating the observation and hidden state values of the last two months for the predictable periods by solving the evaluation and optimal state sequence problems of HMMs, comparisons with actual data were performed in order to determine the consistency of predictions.

Several studies in the literature demonstrate the changing predictability in stock markets. In compliance with the outcomes of AMH examination in this study, it was seen that the return predictability varied over time similar to the studies of Lim (2007), Kim et al. (2011), Smith (2012), Ghazani \& Araghi (2014), Gyamfi (2018), Eyüpoğlu \& Eyüpoğlu (2020) and Obelade \& Muzindutsi (2020). Therefore, it can be mentioned that market efficiency cannot be asserted as an all-or-nothing condition for Borsa Istanbul since there have been some periods of obvious predictability and some periods of unpredictability in compliance with the changing market conditions for the period that this study covers. In the 
performed analysis, firstly we found that the automatic portmanteau and GS tests yielded similar results, as high return predictability was seen between 1988-1990 and around 1993. By considering the financial outlook in Turkey during this period, it can be stated the Turkish Lira was over-valued, and just like the current account deficit, the foreign trade deficit also widened due to the slowdown in exports while imports were increasing (Şahin, 2009: 213). Therefore, as a result of the deterioration in financial markets, Borsa Istanbul (as known as the Istanbul Stock Exchange before 2013) has experienced a rapid decline as of that period (Hatiboğlu \& Aysan, 1994: 51). On the other hand, it was stated that the implementation of financial liberalization since the beginning of the 1980s in Turkey, continued with the removal of restrictions on capital movements in 1989 and because of these, the financial markets have become vulnerable to speculative attacks and acquisitions (Boratav, 2013: 174-186). Hence, these may be regarded as the main reasons for the return predictability and inefficient market conditions for the aforementioned period. Similar findings were also obtained in the study of Eyüpoğlu \& Eyüpoğlu (2020) in which no sign of market efficiency was observed in 1993. In continuation, following years until 2008 mostly present unpredictable behaviour of stock returns for both of the applied tests. It means that with insignificant AQ and p-values of GS tests, there was evidence of market efficiency during these years. After the global crisis in 2007-2008, Boratav (2013) mentioned that the Turkish economy became fragile and once again vulnerable to speculative attacks and acquisitions due to the rapidly increasing current account deficit. Thereby, it can be clearly expressed that significant test results around 2008 indicate strong evidence of predictable stock returns and inefficient market properties in accordance with the financial outlook of this period. This result can also be regarded as consistent with the findings in the study of Lazăr et al. (2012) in which the consequences of the global economic and financial crisis in foreign exchange markets such as Turkey, Russia, Czechia, Romania, etc. have been investigated. Similar to our findings, the results of this study indicated changing behaviours of return predictability over time, which is also consistent with the AMH. Eyüpoğlu \& Eyüpoğlu (2020) also documented the same outlook for this period in Turkey. The influence of the global crisis on market efficiency, hence, the return predictability was thereby revealed by the results of performed linear and nonlinear tests. On the other hand, this outcome contradicts the findings of Zhou \& Lee (2013) in which highly volatile periods such as times of financial crisis are considered to have a negative impact on return predictability. Lastly, the applied tests did not yield significant results after 2008, which show no return predictability until the end of the sample period.

In conclusion, obtained results suggest that efficiency is neither an absolute characteristic nor an invalid scenario but a time-varying feature of Borsa Istanbul. This outcome can be regarded as in line with the previous studies in the literature, as there was no consensus in the related studies regarding the validity of EMH for the Borsa Istanbul. Thereby, it can be stated that the Borsa Istanbul stock market supports the AMH over the period between 1988 and late 2017 as both linear and nonlinear stock return predictability varies over time.

Thereafter for the HMM application, periods with predictability were determined as of February 1991 - September 1993 and February 2008 - October 2008 by considering the 
similar results of the applied tests and data accessibility. After estimating the change ratios of the series regarding the observation and hidden state variables, the transition, observation, and initial state probabilities were calculated, and related symbols were assigned. Subsequently, the evaluation and optimal state sequence problems were solved for the August 1993 - September 1993 and September 2008 - October 2008 periods, thereby forecasts were obtained. According to the results, both periods yielded highly consistent predictions except for the money supply variable's February 1991 and October 2008 values. In conclusion, it can be stated that apart from small deviations, obtained results confirmed the periodic predictability for the determinants of the BIST100 index due to the fact that the estimation values obtained for the observation series and hidden states are almost in line with the actual data.

By considering the policy implications, the findings of this study may serve as a guide to local and international investors who have a particular interest in the Borsa Istanbul as predictable periods in markets direct them to develop strategies to acquire extraordinary gain and thereby increase the profitability of their portfolios. Therefore, it can be stated that depending on market conditions, investors may come across arbitrage and investment opportunities in the Borsa Istanbul. Furthermore, changing characteristics in efficiency hence return predictability may affect the development strategies and regulations in a market. In this context, another policy implication of this study can be regarded as pointing out the necessity of taking measures and incorporate innovations in such times by market regulators, policymakers, and other related decision-makers to avoid problems. As an extension of this study, making use of other tests and alternative approaches that were applied in the literature, also handling periods of varying predictability within detailed historical perspectives with different determinants of indices and methods can be recommended for future researches.

\section{References}

Aga, M. \& B. Kocaman (2011), "Efficient Market Hypothesis and Emerging Capital Markets: Empirical Evidence from Istanbul Stock Exchange”, Journal of Financial Markets Research, 3, 44-57.

Al-Khazali, O. \& A. Mirzaei (2017), "Stock Market Anomalies, Market Efficiency, and The Adaptive Market Hypothesis: Evidence from Islamic Stock Indices", Journal of International Financial Markets, Institutions \& Money, 51, 190-208.

Alvarez-Ramirez, J. \& E. Rodriguez \& G. Espinosa-Paredes (2012), "Is the US Stock Market Becoming Weakly Efficient Over Time? Evidence from 80-Year-Long Data", Physica A, 391, 5643-5647.

Balaban, E. \& H. Baturalp \& K. Kunter (1996), Stock Market Efficiency in a Developing Economy: Evidence from Turkey, Central Bank of Republic of Turkey, Ankara, Türkiye.

Bhar, R. \& S. Hamori (2004), Hidden Markov Models: Applications to Financial Economics, Kluwer Academic Publishers, Dordrecht, Netherlands.

Boratav, K. (2013), Türkiye İktisat Tarihi 1908-2015, İmge Kitabevi Yayınları, İstanbul, Türkiye.

Boya, C.M. (2019), "From Efficient Markets to Adaptive Markets: Evidence from the French Stock Exchange", Research in International Business and Finance, 49, 156-165. 
Buguk, C. \& B.W. Brorsen (2003), "Testing Weak-Form Market Efficiency: Evidence from the Istanbul Stock Exchange”, International Review of Financial Analysis, 12, 579-590.

Butler, M. \& D. Kazakov (2012), "Testing Implications of the Adaptive Market Hypothesis Via Computational Intelligence", IEEE Conference on Computational Intelligence for Financial Engineering \& Economics, 1-8.

Campbell, J.Y. \& A.W. Lo \& A.C. MacKinlay (1997), The Econometrics of Financial Markets, Princeton University Press, New Jersey, USA.

Charles, A. \& O. Darné \& J.H. Kim (2012), "Exchange-Rate Return Predictability and The Adaptive Markets Hypothesis: Evidence from Major Foreign Exchange Rates", Journal of International Money and Finance, 31, 1607-1626.

Charles, A. \& O. Darné \& J.H. Kim (2017), “Adaptive Markets Hypothesis for Islamic Stock Indices: Evidence from Dow Jones Size and Sector-Indices", International Economics, $151,100-112$.

Ching, W.K. \& X. Huang \& M.K. Ng \& T.K. Siu (2013), Markov Chains: Models, Algorithms and Applications, Springer, New York, USA.

Dağlığlu, C. \& G. Kıral (2018), "Hisse Senedi Piyasa Fiyatlarının Saklı Markov Modeli ile Tahmin Edilmesi: Türkiye Örneği”, Uluslararası Ekonomi ve Yenilik Dergisi, 4(1), 61-75.

Dias, J.G. \& J.K. Vermunt \& S. Ramos (2015), "Clustering Financial Time Series: New Insights from an Extended Hidden Markov Model”, European Journal of Operational Research, 243(3), 852-864.

Dionne, G. \& S.S. Hassani (2015), "Hidden Markov regimes in operational loss data: Application to the recent financial crisis", Journal of Operational Risk, 1-40.

Elliott, R.J. \& W.C. Hunter \& B.M. Jamieson (1998), "Drift and Volatility Estimation in Discrete Time", Journal of Economic Dynamics and Control, 22(2), 209-218.

Ertaş, F.C. \& O. Özkan (2018), "Piyasa Etkinliği Açısından Adaptif Piyasa Hipotezinin Test Edilmesi: Türkiye ve ABD Hisse Senedi Piyasaları Örneği”, Finans Politik \& Ekonomik Yorumlar, 642, 23-40.

Escanciano, J.C. \& C. Velasco (2006), “Generalized Spectral Tests for the Martingale Difference Hypothesis”, Journal of Econometrics, 134(1), 151-185.

Escanciano, J.C. \& I.N. Lobato (2009), “An Automatic Portmanteau Test for Serial Correlation”, Journal of Econometrics, 151(2), 140-149.

Eyüpoğlu, K. \& S. Eyüpoğlu (2020), "Borsa İstanbul Endekslerinde Adaptif Piyasa Hipotezinin Geçerliliğinin Test Edilmesi”, Journal of Yasar University, 15(59), 642-654.

Fama, E.F. (1965), "The Behavior of Stock-Market Prices”, The Journal of Business, 38(1), 34-105.

Fama, E.F. (1970), "Efficient Capital Markets: A Review of the Theory and Empirical Work", Journal of Finance, 25(2), 383-417.

Farmer, J.D. \& A.W. Lo (1999), "Frontiers of Finance: Evolution and Efficient Markets", Proceedings of the National Academy of Sciences of the United States of America, 96, 9991-9992.

Ghazani, M.M. \& M.K. Araghi (2014), "Evaluation of the Adaptive Market Hypothesis as an Evolutionary Perspective on Market Efficiency: Evidence from the Tehran Stock Exchange", Research in International Business and Finance, 32, 50-59. 
Ghazani, M.M. \& S.B. Ebrahimi (2019), “Testing the Adaptive Market Hypothesis as an Evolutionary Perspective on Market Efficiency: Evidence from The Crude Oil Prices", Finance Research Letters, 30, 60-68.

Grossman, S.J. \& J.E. Stiglitz (1980), “On the Impossibility of Informationally Efficient Markets”, The American Economic Review, 70(3), 393-408.

Gyamfi, E.N. (2018), “Adaptive Market Hypothesis: Evidence from the Ghanaian Stock Market”, Journal of African Business, 19(2), 195-209.

Hatiboğlu, Z. \& M. Aysan (1994), Türkiye Ekonomisinde 1994 Bunalımı, Beta Basım Yayım, İstanbul, Türkiye.

Hiremath, G.S. \& J. Kumari (2014), "Stock Returns Predictability and the Adaptive Market Hypothesis in Emerging Markets: Evidence from India", SpringerPlus, 3(428), 1-14.

Hiremath, G.S. \& S. Narayan (2016), "Testing the Adaptive Market Hypothesis and Its Determinants for the Indian Stock Markets", Finance Research Letters, 19, 173-180.

Huang, M. \& Y. Huang \& K. He (2019), "Estimation and testing nonhomogeneity of hidden Markov model with application in financial time series", Statistics and Its Interface, 12(2), 215225.

Ibe, O.C. (2013), Markov Processes for Stochastic Modelling, Elsevier, Massachusetts, USA.

Ito, M. \& A. Noda \& T. Wada (2014), "International Stock Market Efficiency: A Non-Bayesian Time-Varying Model Approach”, Applied Economics, 43(23), 2744-2754.

Ito, M. \& A. Noda \& T. Wada (2016), "The Evolution of Stock Market Efficiency in the US: A NonBayesian Time-Varying Model Approach", Applied Economics, 48(7), 621-635.

Kahraman, D. \& M. Erkan (2005), “İstanbul Menkul Kıymetler Borsası’nda Tesadüfi Yürüyüş Testi”, Yönetim ve Ekonomi, 12(1), 11-19.

Khuntia, S. \& J.K. Pattanayak (2018), "Adaptive Market Hypothesis and Evolving Predictability of Bitcoin”. Economic Letters, 167, 26-28.

Khursheed, A. \& M. Naeem \& S. Ahmed \& F. Mustafa (2020), “Adaptive Market Hypothesis: An Empirical Analysis of Time-Varying Market Efficiency of Cryptocurrencies", Cogent Economics \& Finance, 8(1), 1719574.

Kılıç, Y. \& M.F. Buğan (2016), "The Efficient Market Hypothesis: Evidence from Turkey”, International Journal of Academic Research in Business and Social Sciences, 6(10), 262272.

Kim, J.H. \& A. Shamsuddin \& K.-P. Lim (2011), "Stock Return Predictability and the Adaptive Market Hypothesis: Evidence from Century-Long U.S. Data", Journal of Empirical Finance, 18, 868-879.

Kołatka, M. (2020), “Testing the Adaptive Market Hypothesis on the WIG Stock Index: 1994-2019”, Research Papers of Wroclaw University of Economics and Business, 64(1), 131-142.

Langrock, R. \& I.L. MacDonald \& W. Zucchini (2012), "Some Nonstandard Stochastic Volatility Models and Their Estimation Using Structured Hidden Markov Models", Journal of Empirical Finance, 19(1), 147-161.

Lazăr, D. \& A. Todea \& D. Filip (2012), "Martingale Difference Hypothesis and Financial Crisis: Empirical Evidence from European Emerging Foreign Exchange Markets", Economic Systems, 36, 338-350. 
Lekhal, E. \& A. El Oubani (2020), "Does the Adaptive Market Hypothesis Explain the Evolution of Emerging Markets Efficiency? Evidence from the Moroccan Financial Market", Heliyon, 6(7), e04429, 1-12.

Li, N. (2016), Hidden Markov model and financial application, The University of Texas in Austin, Austin, USA.

Lim, K.-P. \& R.D. Brooks (2006), The Evolving and Relative Efficiencies of Stock Markets: Empirical Evidence from Rolling Bicorrelation Test Statistics, <https://ssrn.com/abstract=931071/>, 13.02.2019.

Lim, K.-P. \& W. Luo \& J.H. Kim (2013), “Are US Stock Index Returns Predictable? Evidence from Automatic Autocorrelation-Based Tests", Applied Economics, 45(8), 953-962.

Lim, K.-P. (2007), "Ranking Market Efficiency for Stock Markets: A Nonlinear Perspective", Physica A, 376, 445-454.

Lin, S.-K. \& S.-Y. Wang \& P.-L. Tsai (2009), “Application of Hidden Markov Switching Moving Average Model in the Stock Markets: Theory and Empirical Evidence", International Review of Economics \& Finance, 18(2), 306-317.

Lo, A.W. \& A.C. MacKinlay (1999), A Non-Random Walk Down Wall Street, Princeton University Press, New Jersey, USA.

Lo, A.W. (2004), “The Adaptive Markets Hypothesis: Market Efficiency from an Evolutionary Perspective", Journal of Portfolio Management, 30, 15-29.

Lo, A.W. (2005), "Reconciling Efficient Markets with Behavioral Finance: The Adaptive Markets Hypothesis", The Journal of Investment Consulting, 7(2), 1-24.

Lo, A.W. (2012), “Adaptive Markets and the New World Order”, Financial Analysts Journal, 68(2), 18-29.

Lobato, I. \& J.C. Nankervis \& N.E. Savin (2001), “Testing for Autocorrelation Using a Modified Box-Pierce Q Test", International Economic Review, 42(1), 187-205.

Madhavan, V. \& R. Arrawatia (2016) "Relative Efficiency of G8 Sovereign Credit Default Swaps and Bond Scrips: An Adaptive Market Hypothesis Perspective", Studies in Microeconomics, 4(2), 1-24.

Meng, Q.-B. \& X. Zhang \& J.-N. Bi (2017), “On Optimal Proportional Reinsurance and Investment in a Hidden Markov Financial Market”, Acta Mathematicae Applicatae Sinica English Series, 33(1), 53-62.

Nguyen, N. \& D. Nguyen (2015), "Hidden Markov model for stock selection”, Risks, 3, 455-473.

Noda, A. (2016), “A Test of the Adaptive Market Hypothesis Using a Time-Varying AR Model in Japan”, Finance Research Letters, 14, 66-71.

Nurunnabi, M. (2012), “Testing Weak-Form Efficiency of Emerging Economies: A Critical Review of Literature", Journal of Business Economics and Management, 13(1), 167-188.

Nystrup, P. \& H. Madsen \& E. Lindström (2015), "Stylised Facts of Financial Time Series and Hidden Markov Models in Continuous Time", Quantitative Finance, 15(9), 1531-1541.

Nystrup, P. \& H. Madsen \& E. Lindström (2017), "Long Memory of Financial Time Series and Hidden Markov Models with Time-Varying Parameters", Journal of Forecasting, 36(8), 989-1002.

Obalade, A.A. \& P.F. Muzindutsi (2020), "Validating the Adaptive Market Hypothesis in the Tunisian Stock Market”, International Journal of Trade and Global Markets, 13(1), 42 51. 
Öz, E. (2009), “Saklı Markov Modelleri ve Finansal Bir Uygulama”, İstanbul: Yayınlanmamış Doktora Tezi, Marmara Üniversitesi Sosyal Bilimler Enstitüsü.

Patil, A. \& S. Rastogi (2020), "Multifractal Analysis of Time-Varying Market Efficiency: Implications for Adaptive Market Hypothesis", Test Engineering and Management, 83, 16646-60.

Popović, S. \& A. Mugoša \& Đ. Andrija (2013), “Adaptive Markets Hypothesis: Empirical Evidence from Montenegro Equity Market”, Economic Research, 26(3), 31-46.

Rabiner, L.R. \& B.H. Juang (1986), “An Introduction to Hidden Markov Models”, IEEE ASSP Magazine, 3(1), 4-16.

Rahman, M.L. \& D. Lee \& A. Shamsuddin (2017), "Time-Varying Return Predictability in South Asian Equity Markets", International Review of Economics and Finance, 48, 179-200.

Ramírez, S.C. \& P.L. Arellano \& O. Rojas (2015), “Adaptive Market Efficiency of Agricultural Commodity Futures Contracts”, Contaduría y Administración, 60(2), 389-401.

Reilly, F.K. \& K.C. Brown (2012), Investment Analysis \& Portfolio Management, South-Western Cengage Learning, Ohio, USA.

Rosini, L. \& V. Shenai (2020), "Stock Returns and Calendar Anomalies on the London Stock Exchange in the Dynamic Perspective of the Adaptive Market Hypothesis: A Study of FTSE100 \& FTSE250 Indices over a Ten-Year Period", Quantitative Finance and Economics, 4(1), 121-147.

Rossi, A. \& G.M. Gallo (2006), "Volatility Estimation Via Hidden Markov Models", Journal of Empirical Finance, 13(2), 203-230.

Şahin, H. (2009), Türkiye Ekonomisi, Seçkin Yayıncılık, Ankara, Türkiye.

Shahid, M.N. \& K. Latif \& G.M. Chaudhary \& R. Kouser (2020), "Vacillating Behavior of TOM Effect and Adaptive Market Hypothesis: A Firm-Level Evidence from Emerging Stock Market of Pakistan", Journal of Business and Social Review in Emerging Economies, 6(2), 517-529.

Shiller, R.J. (2003), "From Efficient Markets Theory to Behavioral Finance", The Journal of Economic Perspectives, 17(1), 83-104.

Simon, H.A. (1955), “A Behavioral Model of Rational Choice”, The Quarterly Journal of Economics, 69(1), 99-118.

Smith, G. (2012), "The Changing and Relative Efficiency of European Emerging Stock Markets", The European Journal of Finance, 18(8), 689-708.

Thomas L.C. \& D.E. Allen \& N. Morkel-Kingsbury (2002), "A Hidden Markov Chain Model for the Term Structure of Bond Credit Risk Spreads", International Review of Financial Analysis, 11(3), 311-329.

Ţiţan, A.G. (2015), "The Efficient Market Hypothesis: Review of Specialized Literature and Empirical Research", Procedia Economics and Finance, 32, 442-449.

Todea, A. \& M. Ulici \& S. Silaghi (2009), “Adaptive Markets Hypothesis: Evidence from AsiaPacific Financial Markets", The Review of Finance and Banking, 1(1), 7-13.

Tripathi A. \& V. Vipul \& A. Dixit (2020), "Adaptive Market Hypothesis and Investor Sentiments: Global Evidence", Managerial Finance, 46(11), 1407-1436.

Urquhart, A. \& F. McGroarty (2016), “Are Stock Markets Really Efficient? Evidence of the Adaptive Market Hypothesis”, International Review of Financial Analysis, 47, 39-49. 
Urquhart, A. \& R. Hudson (2013), "Efficient or Adaptive Markets? Evidence from Major Stock Markets Using Very Long Run Historic Data", International Review of Financial Analysis, 28, 130-142.

Verheyden, T. \& F.V. Bossche \& L.D. Moor (2013), “Towards a New Framework on Efficient Markets: A Rolling Variance Ratio Test of the Adaptive Market Hypothesis", Research in International Business and Finance, 34, 294-308.

Y1lmaz, N.T. \& T. Can (2016), "The Analysis of Foreign Direct Investment with Hidden Markov Model: Evidence from Turkey", International Journal of Economic Perspectives, 10(2), 117-133.

Yılmaz, N.T. (2015), Türkiye’ye Gelen Doğrudan Yabancı Sermaye Yatırımları Üzerine Gizli Markov Modeli Uygulaması, Marmara Üniversitesi Sosyal Bilimler Enstitüsü, İstanbul, Türkiye.

Zhang, B. (2013), "Are the Crude Oil Markets Becoming More Efficient Over Time? New Evidence from a Generalized Spectral Test", Energy Economics, 40, 875-881.

Zhang, M. \& X. Jiang \& Z. Fang \& Y. Zeng \& K. Xu (2019), "High-Order Hidden Markov Model for Trend Prediction in Financial Time Series", Physica A: Statistical Mechanics and its Applications, 517, 1-12.

Zhou, J. \& J.M. Lee (2013), “Adaptive Market Hypothesis: Evidence from The REIT Market”, Applied Financial Economics, 23(21), 1649-1662. 